INTERNATIONAL CENTER FOR PUBLIC POLICY
International Center for Public Policy

Working Paper 18-23

November 2018

\title{
A Theoretical Rationale for the Fiscal Gap Model of Equalization Transfers
}

Jorge Martinez-Vazquez

Cristian Sepulveda

\section{ANDREWYOUNG SCHOOL}





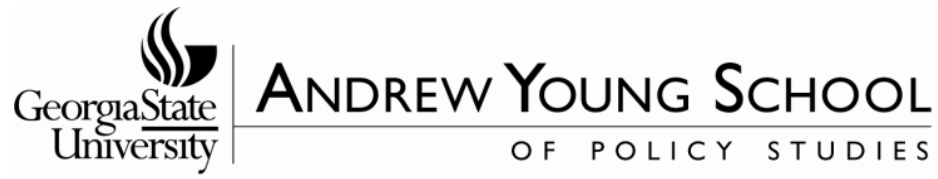

International Center for Public Policy Working Paper 18-23

\title{
A Theoretical Rationale for the Fiscal Gap Model of Equalization Transfers
}

\author{
Jorge Martinez-Vazquez \\ Cristian Sepulveda
}

November

2018

International Center for Public Policy

Andrew Young School of Policy Studies

Georgia State University

Atlanta, Georgia 30303

United States of America

Phone: (404) 413-0235

Fax: (404) 651-4449

Email: paulbenson@gsu.edu

Website: http://icepp.gsu.edu/

Copyright 2018, the Andrew Young School of Policy Studies, Georgia State University. No part of the material protected by this copyright notice may be reproduced or utilized in any form or by any means without prior written permission from the copyright owner. 


\section{International Center for Public Policy Andrew Young School of Policy Studies}

The Andrew Young School of Policy Studies was established at Georgia State University with the objective of promoting excellence in the design, implementation, and evaluation of public policy. In addition to two academic departments (economics and public administration), the Andrew Young School houses seven leading research centers and policy programs, including the International Center for Public Policy.

The mission of the International Center for Public Policy (ICePP) at the Andrew Young School of Policy Studies is to provide academic and professional training, applied research, and technical assistance in support of sound public policy and sustainable economic growth in developing and transitional economies.

ICePP is recognized worldwide for its efforts in support of economic and public policy reforms through technical assistance and training around the world. This reputation has been built serving a diverse client base, including the World Bank, the U.S. Agency for International Development (USAID), the United Nations Development Programme (UNDP), finance ministries, government organizations, legislative bodies, and private sector institutions.

The success of ICePP reflects the breadth and depth of its in-house technical expertise. The Andrew Young School's faculty are leading experts in economics and public policy and have authored books, published in major academic and technical journals, and have extensive experience in designing and implementing technical assistance and training programs. Andrew Young School faculty have been active in policy reform in over 40 countries around the world. Our technical assistance strategy is not merely to provide technical prescriptions for policy reform, but to engage in a collaborative effort with host governments and donor agencies to identify and analyze the issues at hand, arrive at policy solutions, and implement reforms.

ICePP specializes in four broad policy areas:

- Fiscal policy (including tax reforms, public expenditure reviews, tax administration reform)

- Fiscal decentralization (including decentralization reforms, design of intergovernmental transfer systems, urban government finance)

- Budgeting and fiscal management (including local government budgeting, performancebased budgeting, capital budgeting, multi-year budgeting)

- Economic analysis and revenue forecasting (including micro-simulation, time series forecasting)

For more information about our technical assistance activities and training programs, please visit our website at http://icepp.gsu.edu or contact us by email at paulbenson@gsu.edu. 


\title{
A Theoretical Rationale for the Fiscal Gap Model of Equalization Transfers
}

\author{
Jorge Martinez-Vazquez and Cristian Sepulveda*
}

November 2018

\begin{abstract}
Equalization transfers are a common and noteworthy feature of fiscal decentralization systems around the world, especially in developing countries. However, the way in which they are designed and implemented is not clearly rooted in mainstream public finance theory. In this paper we develop a formal framework to explain the rationale of the fiscal gap model (the difference between expenditure needs and fiscal capacity of a jurisdiction), arguably the most popular model used by applied economists for the design of equalization transfer programs. First we take into account the problem of accountability. If government authorities are selfinterested, transfers from upper levels are shown to reduce their responsiveness to taxpayers' preferences. Next, we use a normative approach to derive the conventional fiscal gap formula. We argue that equalization transfers should only be used to finance limited types and amounts of public expenditures, called here standard public expenditures. In contrast, discretional public expenditures (not subject to equalization) should be financed exclusively with own revenues. Last, we describe the conditions that ensure the affordability of the system. We conclude that the fiscal gap model of equalization is sufficient to efficiently allocate the available funds across jurisdictions, setting the marginal cost of funds at the appropriate level. However, no information on the marginal cost of funds is required. Policymakers can simply rely on estimates of expenditure needs and fiscal capacity to design an optimal equalization transfer program.
\end{abstract}

Keywords: fiscal federalism, equalization transfers, optimal taxation, marginal cost of funds, public expenditures

JEL classification: $\mathrm{H} 21, \mathrm{H} 40, \mathrm{H} 71$

\footnotetext{
* Martinez-Vazquez: Georgia State University, Atlanta, Georgia, United States (jorgemartinez@gsu.edu); Sepulveda: Farmingdale State College (SUNY), Farmingdale, New York, United States (cristian.sepulveda@farmingdale.edu)

We are grateful to Robin Boadway, Richard Bird, Bev Dahlby, Charles McLure, Vito Tanzi, François Vaillancourt, Otavio Bartalotti, and Steven Sheffrin for useful comments and suggestions to previous versions of this paper.
} 


\section{Introduction}

The design of an optimal equalization transfer program has been the focus of an extensive research in the literature of fiscal federalism. The model of fiscal gaps, which allocates equalization transfers in accordance to the differences between expenditure needs and fiscal capacities, is arguably the dominant model used by applied economists in fiscal decentralization reforms around the world. This model has been championed by international organizations like the World Bank, the United Nations, and bilateral donors in many developing countries over the past several decades (Boadway and Shah 2007; Martinez-Vazquez and Searle 2007). However, in spite of its widespread use, the design of equalization transfers based on the fiscal gap model has not been directly rooted in mainstream public finance theory, and applied economists routinely struggle to establish its theoretical underpinnings.

The objective of this paper is to provide a theoretical rationale for the fiscal gap model. Even though the literature has long recognized the importance of effective tax and expenditure autonomy to foster efficiency and ensure the presence of accountability mechanisms (Bird and Smart 2002; Bahl and Martinez-Vazquez 2006), and equalization transfers have already been analyzed in the framework of optimal tax theory (Dahlby and Wilson 1994; Boadway and Keen 1996; Bucovetsky and Smart 2006; Dahlby 2009), to date it is not clear if and how the fiscal gap model can be used to implement an optimal equalization transfer program. ${ }^{1}$ We show that the fiscal gap model is compatible with the notion of an optimal equalization transfer program and explain what applied economists and policymakers should consider in order to implement such program.

\footnotetext{
${ }^{1}$ For a wide discussion of equalization transfers and the fiscal gap model, see Martinez-Vazquez and Searle (2007). Note that we use the term "subnational" to refer to any government unit below the central or "national" level. The analysis in the paper is applicable to any subnational level.
} 
The framework presented in this paper is divided in three stages, intended to integrate the main normative goals and practical constraints faced by policymakers in the design and implementation of an equalization grant based on the fiscal gap model. The first stage deals with the role of equalization transfers in the broader context of the revenue assignment problem and the need to limit their amount due to possible negative effects on accountability and government responsiveness. Fiscal decentralization experts have long claimed that taxpayers hold authorities accountable only (or mostly) when public expenditures are financed with own tax revenue; consequently, transfers are expected to reduce accountability, government responsiveness, and tax effort (Faguet 2004; Blöchliger and Charbit 2008; Liu and Zhao 2011). We provide theoretical support for this claim, and argue that the devolution of substantial own revenue sources is a precondition for a well-functioning equalization transfer program. An incentive-compatible equalization transfer program must penalize inefficient decisions without hindering subnational fiscal autonomy.

The second stage focuses on the design of an optimal equalization transfer program. As it is explicitly or implicitly done in most federal and decentralized countries, we assume that the goal of the equalization transfer program is to ensure that all subnational governments are able to provide a standard level of public goods and services at a standard level of tax effort. We argue that the optimal transfer system should be computed under the assumption of perfect government responsiveness, and with the use of a standard tax rate and a standard administrative cost function. In this framework, irresponsive and inefficient governments are penalized with lower equalization transfers. We distinguish standard public expenditures, which should be subject to equalization, from discretional public expenditures, which should not be subject to equalization. Once equalization transfers have been assigned, subnational governments should enjoy "autonomy at the 
margin,"2 interpreted here as the discretional use of tax policy to finance autonomous or discretional (non-standard) public expenditures. Finally, in the third stage we obtain the optimal conditions that ensure the affordability of the equalization transfer program.

A relevant concern is the practical relevance of some policy prescriptions for equalization transfer design derived from the framework of optimal tax theory. In particular, it is not realistic to expect that central government authorities and politicians will be able to equalize the marginal cost of public funds across jurisdictions. In practice, this is an abstract concept that is normally absent from policy debates. In this paper, we show that in fact policy makers do not need to observe the marginal cost of funds to implement the optimal revenue assignment policy. Instead, the fiscal gap model is sufficient to design an equalization transfer program that tacitly sets the marginal cost of funds at the appropriate level. In practice, policy makers can focus only on defining what subnational services are to be considered as part of the national standards and the size of the equalization transfer fund.

The remains of the paper is structured as follows. Section 2 analyzes the first stage of the model, focused on the problem of limited government responsiveness in a context where authorities are self-interested and accountability is imperfect. Section 3 presents the second stage of the model, focused on the normative problem of designing the optimal amount of equalization transfers, and showing how the fiscal gap model is sufficient to implement this program. Section 4 presents the optimal conditions for the system that implements the equalization transfer program to be affordable. Section 5 concludes.

\footnotetext{
2 This rule was first put forward by McLure (2000), and its rationale is closely related to Oates' (1972) Decentralization Theorem, according to which, whenever centralized expenditure policies are common across jurisdictions and preferences are heterogeneous, social welfare can be increased by decentralized autonomous decision-making. Effective autonomy in the expenditure side of the budget, however, requires autonomy to change the amount of revenues; thus, the ability to efficiently satisfy local preferences calls for both expenditure and revenue autonomy at the margin.
} 


\section{Accountability and the effect of transfers on government responsiveness}

All intergovernmental transfers have the potential of introducing perverse incentives in the decentralization system by reducing accountability and public responsiveness, and even tax effort. In this section, we examine what conditions should an equalization transfer program satisfy so to avoid those undesirable effects.

Accountability can be understood as the ability of individuals to use political support (or lack thereof) to improve the fiscal decisions of government authorities, who may be concerned not only about social welfare but also (or instead) about their own selfish benefits. In this context, more accountability leads to a more responsive government, and thus to a better match of fiscal decisions with individuals' needs and wants. Accountability has been mostly addressed in the political economy literature, which has focused on the different factors that may affect accountability and the degree of preference matching in centralized versus decentralized systems of government (Lockwood 2005; Bardhan 2002; Besley and Coate 2003). This literature suggests that accountability increases with revenues that are collected inside the jurisdiction, or equivalently, it decreases with windfalls and transfers from outside the jurisdiction.

However, this claim has only recently begun to be empirically tested. Brollo et al. (2013) develop a political agency model and show that an increase in transfers, as opposed to own revenues, is associated with greater corruption. Using village-level data from an Indonesian district, Paler (2013) shows that own taxation provides stronger incentives than windfall transfers to monitor the budget and constrain the government. Similarly, Gadenne (2017) finds that increases in local taxes in Brazilian municipalities have positive effects on the quality of local public infrastructure, while equal increases in intergovernmental transfers do not. 
Even though this previous literature is suggestive of the type of problems that can arise with accountability in the design of a system of intergovernmental transfers, so far there has been a lack of formalization of what are the institutional requirements for the design of an optimal equalization transfer. In this section, we present a simple reduced-form model of accountability from which we derive three conditions for that optimal design: own-revenue, incentivecompatibility, and expenditure autonomy. The model is based on the concept of net fiscal benefits, which is defined for each taxpayer as the difference between the benefits received from government expenditures and the costs of financing those expenditures with taxes. Fiscal policies that increase taxpayers' welfare are rewarded with greater political support, and government authorities maximize a function that depends on political benefits as well as the gains from diverting public funds for their personal use. The model shows that intergovernmental transfers reduce local government responsiveness and reveals the conditions that need to be met in order to counter low responsiveness.

The preferences of the representative taxpayer are represented by a concave utility function $u$ that increases with the consumption of the private good $x$ and the local public good available in the jurisdiction, $G$, which may plausibly be fully congestible. We do not model taxpayer's behavior fully. Instead, throughout the paper we will assume for simplicity that there is only one tax instrument and that an increase in the tax rate $t$ triggers behavioral responses (in labor supply, tax evasion and tax avoidance) of the representative taxpayer, reducing the size of the tax base $B=$ $B(t)$, such that $B_{t}<0$, where the subscript represents a derivative.

Subnational governments can finance public goods with own tax revenue or with exogenous intergovernmental transfers from the central government, $T$. Own revenue collection is assumed to be associated with a cost function $A$, which summarizes all the monetary costs of 
administration, collection and enforcement. ${ }^{3}$ This cost function is assumed to be differentiable and increasing in the amount of revenues collected, $t B(t) .{ }^{4}$ Net own revenues are given by $R(t)=$ $t B(t)-A[t B(t)]$

In order to model the accountability mechanism we introduce the choice variable $\rho \in[0,1]$, defined as subnational government responsiveness to the representative taxpayer's preferences, or the extent to which government decisions about public goods provision truthfully represent the preferences of the constituents. If $\rho=1$, government expenditures perfectly represent the preferences of the constituents. A value lower than unity implies that a share $1-\rho$ of subnational government funds is "wasted", due to the inaccurate representation of preferences, neglect, production inefficiencies, corruption, or fraud. The amount of public goods and services effectively provided by the subnational government is $G(t, \rho, T)=\rho(R(t)+T)$, while the amount of resources diverted from which authorities can obtain personal benefits is $(1-\rho)(R(t)+T)$.

Fiscal policies of the subnational government provide net fiscal benefits to the representative taxpayer, who in turn is assumed to provide political support to government authorities in accordance to the net fiscal benefits received. Private consumption is $X(t)=$ $(1-t) B(t)$ and the utility of the representative taxpayer is described by $u(X(t), \rho(R(t)+T))=$ $v(t, \rho, T)$, where $v$ is the indirect utility function. The individual marginal net benefits of an increase of $t$ - which is also the marginal net fiscal incidence of the tax - is given by:

$$
v_{t}=X_{t} u_{X}+\rho R_{t} u_{G} \cdot(1 . a)
$$

\footnotetext{
${ }^{3}$ The costs associated with the use of taxation could possibly include the political costs faced by government authorities, as considered by Hettich and Winer (1984). In our analysis, however, political costs and benefits will be defined separately in an explicit way.

${ }^{4}$ We acknowledge that revenue collection technologies might be more complex. For instance, Slemrod and Yitzhaki (2002) argue that tax administration cost functions may be discontinuous because slight changes in administrative practices and policy decisions lead to discrete changes in administrative costs.
} 
$v_{t}$ can be greater, lower, or equal to zero, meaning that the individual taxpayer can gain, lose, or be indifferent about an increase of $t$. Provided that $X_{t}<0$, when public goods are relatively scarce we can expect $u_{G}$ to be high with respect to $u_{X}$, and thus $v_{t}$ to be positive. Assuming diminishing marginal utility, as $t$ increases, and public goods become more abundant, $v_{t}$ decreases and eventually becomes negative. In contrast, a marginal increase of government responsiveness $\rho$ will always increase net fiscal benefits, of course, bounded by its maximum value:

$$
v_{\rho}=(R(t)+T) u_{G}>0(1 . b)
$$

In this model political gains of government authorities are expected to move in the same direction as taxpayers' net fiscal benefits. For simplicity, we first assume that they have the same value. Subnational authorities can gain political support by adjusting $t$ toward the level at which $v_{t}=0$ (where net fiscal benefits are maximized) or by increasing $\rho$. Note that subnational authorities may altruistically value voters' welfare and support, or may instead be selfishly concerned about avoiding removal from office or increasing the probability of reelection, as the means to maximize individual rents. Either motive has the same effect of protecting the interests of voters. In practice, however, accountability can only be an issue when subnational authorities are negligent or pursue their own agenda, which implies that subnational authorities cannot longer be assumed to be purely benevolent and efficient.

Subnational authorities are assumed to choose $t$ and $\rho$ in order to maximize a concave benefit function that comprises the political gains they obtain from the overall level of net fiscal benefits, measured initially by the utility of the representative taxpayer, and the share of public funds diverted for uses different from the efficient provision of public goods: ${ }^{5}$

\footnotetext{
${ }^{5}$ Once we incorporate the proportion of waste of public funds $\rho$, we may also consider that a share of "active waste" $\delta$ will report direct benefits to the corrupted government officials (see Bandiera et al 2009 for the distinction between active and passive waste and a theoretical and empirical analysis). In that case, the decision maker may use the term $(1-\rho) \delta R$ in the objective function, which would show the tradeoff between improving social welfare and increasing
} 


$$
\Omega=v(t, \rho, T)+(1-\rho)(R(t)+T) .
$$

The first order conditions are:

$$
\begin{gathered}
t: v_{t}=-(1-\rho) R_{t},(2 . \mathrm{a}) \\
\rho: v_{\rho}=R(t)+T .(2 . \mathrm{b})
\end{gathered}
$$

Note that as long as $R_{t}>0$, which is what we expect from a benefit-maximizer government, $u_{t}$ must be negative at the optimal $t$. Given diminishing marginal utility of private and public goods, this means that the subnational government will generally choose a tax rate that is higher than the level necessary to maximize taxpayers' welfare and political gains.

We are particularly interested in the effect of exogenous transfers $T$ on optimal government responsiveness. A negative (positive) effect of $T$ on $\rho$ implies that transfers worsen (improve) accountability and responsiveness. First, we consider the case in which the representative taxpayer fully accounts for all the effects of $T$ on her net fiscal benefits. Using comparative statics, the effect is given by: ${ }^{6}$

$$
\frac{d \rho}{d T}=\frac{\left(v_{t t}+(1-\rho) R_{t t}\right)\left(1-\rho v_{\rho \rho}\right)+\left(v_{\rho t}-R_{t}\right) v_{t T}}{\left(v_{t t}+(1-\rho) R_{t t}\right) v_{\rho \rho}-\left(v_{\rho t}-R_{t}\right)^{2}}
$$

Quasi-concavity requires the denominator (the determinant of the Hessian) to be positive, thus the sign of the expression will be the same as the sign of the numerator. Since it is not clear what the sign of $v_{\rho t}$ and $v_{t T}$ are, the effect of $T$ on $\rho$ is ambiguous. At this point we can conclude that when political support is assumed to be equal to net fiscal benefits, it is not possible to predict a negative effect of transfers on government responsiveness.

their own gains. This term would be relevant for describing a more general solution to the problem at hand, but would not significantly change the implications of our model of accountability. Thus, for simplicity we will assume $\delta=0$ and restrict the scope of the model to a wide range of inefficiencies, which may or may not involve corruption.

${ }^{6}$ Derivation in Appendix I. 
The argument put forward by applied economists, however, is that accountability is imperfect and taxpayers care (or care much more) about the performance of government authorities only when public expenditures are financed with their own money. More than an assumption, imperfect accountability is also a logical requirement of the model, because local authorities can take advantage of public office only if they are not subject to perfect oversight and political control from their constituents. In order to incorporate this argument, we assume that $T$ cannot be fully observed by the taxpayers. ${ }^{7}$ Consistent with those assumptions, we represent political support with the function $\pi=\pi(t, \rho)$, which is assumed to accumulate the marginal net fiscal benefits of $t$ and government responsiveness $\rho$, but it does not directly vary with $T$. Therefore, by definition $\pi_{T}=0$, and changes in $T$ can affect political support only through their influence on $t$ and $\rho$. The objective function for the subnational authorities and the first order conditions are rewritten as

$$
\begin{gathered}
\Omega^{\prime}=\pi(t, \rho)+(1-\rho)(R(t)+T), \\
t: \pi_{t}=-(1-\rho) R_{t},(3 . \mathrm{a}) \\
\rho: \pi_{\rho}=R(t)+T .(3 . \mathrm{b})
\end{gathered}
$$

Using comparative statics, the effect of $T$ on $\rho^{*}$ is: ${ }^{8}$

$$
\frac{d \rho}{d T}=\frac{\pi_{t t}+(1-\rho) R_{t t}}{\left(\pi_{t t}+(1-\rho) R_{t t}\right) \pi_{\rho \rho}-\left(\pi_{\rho t}-R_{t}\right)^{2}}
$$

Under diminishing marginal utility and assuming $R_{t t} \leq 0$, the numerator of the right hand side is negative, which implies that intergovernmental transfers reduce government responsiveness. ${ }^{9}$ The

\footnotetext{
${ }^{7}$ An alternative way to justify this assumption follows from observing that even if information about the amount of transfers is made fully available to the taxpayers, that information is meaningless if they do not know the costs of providing public goods and services.

${ }^{8}$ Derivation is shown in Appendix II.

${ }^{9}$ The assumption $R_{t t} \leq 0$ is standard in the literature, and can be considered a second order requirement for the existence of an interior solution. To see this, note that, $R_{t t}>0$ implies that the productivity of a tax instrument
} 
reason is that transfers give the authorities more "room to cheat," so that they can reduce responsiveness without reducing (or even increasing) their political gains. This result is consistent with the predictions and empirical findings of Brollo et al (2013) and Gadenne (2017), who find that transfers worsen accountability. The conclusion is that responsiveness improves with own tax revenue, and that accountability is maximized when $T=0$.

An advantage of the reduced-form model just described is that it can be easily linked to the standard maximization model used in the analysis of second-best government decisions. Using the assumption that $\pi_{t}=v_{t}$ and $\pi_{\rho}=v_{\rho}$ at the optimal solution, we can rely on (2.b) and (2.c) to obtain the condition for the optimal amount of government expenditures: ${ }^{10}$

$$
\frac{u_{G}}{u_{x}}=\frac{-X_{t}}{R_{t}}(5)
$$

which is the adjusted Samuelson condition for the optimal amount of public expenditures under a second-best scenario where lump-sum taxation is unavailable. The right hand side corresponds to the marginal cost of public funds (MCF), a measure of the welfare costs paid by society for a marginal increase in government revenues. ${ }^{11}$ This result shows that the traditional adjusted Samuelson condition, normally derived under the assumption of benevolent government, is also meaningful in more realistic scenarios where the government is not benevolent.

However, it is important to note that condition (5) does not describe the welfare maximizing solution when $\rho<1$. The right hand side of the condition underestimates the MCF of the representative taxpayer because it considers as gains the rents received by subnational

\footnotetext{
increases with the tax rate. Other things equal, public goods and services become cheaper with higher tax rates and there would be no reason to choose a tax rate lower than $100 \%$.

${ }^{10}$ Provided $\pi_{t}=v_{t}$ and $\pi_{\rho}=v_{\rho}$, we can use (2.a), (2.b), (3.a) and (3.b) to show that at the optimal response in (4), $v_{\rho}=-(R(t)+T) v_{t} /(1-\rho) R_{t}$. Making the right hand side of this equation equal to the right hand side of (1.b), and rearranging, $v_{t}=-(1-\rho) R_{t} u_{G}$. Substituting into (1.a) we can obtain (5).

${ }^{11}$ Ballard and Fullerton (1992) and Dahlby (2008) provide extensive discussions of the concept of the marginal cost of funds. Examples of formal definitions of the concept can be found also in Håkonsen (1998) and Auerbach and Hines (2002).
} 
authorities, which are not shared with the rest of society. ${ }^{12}$ Provided $\rho<1$, the tax rate that maximizes the utility of the representative taxpayer can be described by $v_{t}=0$. Using (1.a), we obtain

$$
\frac{u_{G}}{u_{x}}=\frac{-X_{t}}{\rho R_{t}}(6)
$$

which is the adjusted Samuelson condition after correcting for limited government responsiveness. The right hand side is the "true" MCF faced by the representative taxpayer and, as expected, it increases with the reduction of $\rho .^{13}$

Figure 1 describes the effect of intergovernmental transfers on the optimal amount of public goods. The horizontal axis represents public expenditures and the vertical axes the marginal costs and benefits of public funds. The demand for government expenditures is given by the representative taxpayer's marginal rate of substitution between public and private goods, which is assumed to be decreasing. The supply of public expenditures corresponds to the MCF, which is a function of $t, \rho$, and $T$. In particular, the MCF function is assumed to be increasing in $t$. The initial equilibrium $e^{1}$ corresponds to a situation without transfers, where government responsiveness $\rho$ is at its maximum value, assumed here to be 1 , and the optimal MCF faced by the jurisdiction is $M C F^{1}$. The effect of an exogenous amount of intergovernmental transfers $T$ is to shift the MCF function from $M C F^{\prime}$ to $M C F^{\prime \prime}$ and to move the equilibrium to $e^{2} \cdot{ }^{14}$ Transfers allow the government

\footnotetext{
${ }^{12}$ To see this, knowing that $\pi_{\rho}=v_{\rho}$ we can use (1.b) and (2.b) to show that $u_{G}=1$. Replacing this value into (1.a) and equating the right hand sides of (1.a) and (2.a) we obtain $\left(X_{t} u_{X}+\rho^{*} R_{t}\right)+\left(R_{t}-\rho^{*} R_{t}\right)=0$. It is easy to see that an increase in $\rho^{*}$ leads to additional political gains (the term $\rho^{*} R_{t}$ in the first parenthesis) which are exactly offset by the reduction in individual rents (the term $-\rho^{*} R_{t}$ in the second parenthesis).

${ }^{13}$ The MCF faced by a local community considers only the welfare costs borne inside the jurisdiction. The welfare costs borne by taxpayers outside the jurisdiction, due for instance to the negative effect that $t$ may have on the central government tax collections, are normally disregarded by subnational authorities. We come back to this issue in section 4 , where we analyze the problem of revenue decentralization in the presence of tax externalities.

${ }^{14}$ More commonly, intergovernmental transfers are associated with positive, although relatively low or subsidized, marginal costs to subnational governments. This is because a share of the transfers received may have been financed with taxes collected inside the jurisdiction, and so they may either erode subnational tax bases or require some degree of subnational tax effort. Revenue sharing on a derivation basis is an example of transfers fully financed with internally-raised taxes.
} 
to substitute away own tax collections (reduced from $G^{1}$ to $R^{2}$ ), while increasing public goods provision and reducing the optimal MCF from $M C F^{1}$ to $M C F^{2} \cdot{ }^{15}$

The equilibrium $e^{2}$ describes the optimal choice of self-interested government authorities, but not the amount of public goods available to the representative taxpayer. In accordance to (4) and (6), transfers reduce government responsiveness and thus shift the representative taxpayer's MCF function to $M C F^{\prime \prime \prime}$. The amount of public goods actually available to the representative taxpayer is $G^{2}$, found by evaluating $M C F^{\prime \prime \prime}$ at the marginal cost $M C F^{2}$. The welfare maximizing solution described in (6) is found at $e^{3}$, but that point is no longer feasible.

\section{Figure 1}

Effect of transfers on optimal government expenditures

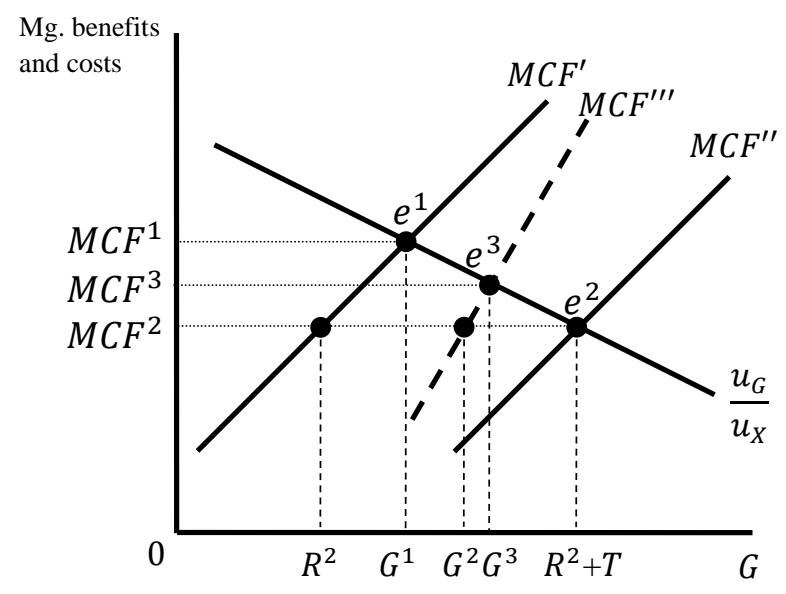

Thus, if provided in the right amount, intergovernmental transfers allow subnational governments to reach more efficient and/or fairer levels of expenditures, but at the cost of worsening government responsiveness. The thought experiment presented in Figure 1 can now be used to highlight three "conditions" for the design of an optimal equalization transfer system. None of these conditions have been adequately addressed in the previous theoretical literature.

\footnotetext{
${ }^{15}$ A similar result is found in Smart (1998), although based in a different reasoning. He argues that equalization transfers reduce the MCF because they help to avoid part of the distortionary effects of local tax increases. See Dahlby (2008, p.247) for additional discussion.
} 
First, we have what we will call the own-revenue condition. Since transfers worsen government responsiveness, they increase the MCF faced by the representative taxpayer at any given level of public goods provision - as illustrated by the shift from $M C F^{\prime \prime}$ to $M C F^{\prime \prime \prime}$ in Figure 1. Moreover, even though intergovernmental transfers can usually be expected to reduce the MCF and stimulate public goods provision - as illustrated in the change from $e^{1}$ to $e^{3}-$ the opposite result is also possible if they induce a significant loss of government responsiveness. The negative effects of intergovernmental transfers on government responsiveness and the effective MCF call for a measured use of transfers and the promotion of own sources of revenue for the financing of local governments.

Second, we have the incentive-compatibility condition. In the presence of limited government responsiveness, the representative taxpayer's welfare maximizing amount of public goods $G^{3}$ is neither feasible nor desirable. In the model developed in this section, self-interested government authorities will choose to collect an amount of $R^{2}$ in tax revenue, and to provide public goods by $G^{2}$. It is not immediately clear what amount of public goods provision should an equalization transfer system try to reach. For instance, reaching an amount equal to $R^{2}+T>G^{3}$, would require additional transfers and therefore lead to a larger lack of responsiveness.

Third, we have the expenditure autonomy condition. The question about the desired amount of public goods and services cannot be clarified without creating a new problem related with the level of autonomy that subnational authorities should enjoy in a decentralized system of government. If some of the gains from fiscal decentralization are realized because local authorities are better positioned to tailor fiscal decisions to taxpayers' preferences (Oates 1972), then the final equilibrium should be determined by local policies, not by exogenous transfers. In this sense, an important limitation of intergovernmental transfers is that they are not necessarily an effective tool 
to enhance decision making autonomy in expenditure choices. As McLure (2000, p. 626) puts it, subnational expenditure autonomy requires that subnational governments are "able to control the level of revenue at the margin; that is, they must be able to set the level of taxes to correspond to the desires of voters". ${ }^{16}$ Following this argument the optimal MCF faced by the representative taxpayer should be allowed to vary in each jurisdiction in accordance to the local demand for public goods and services, while the amount of transfers should not be affected by the autonomous decisions made in different jurisdictions.

\section{Designing the welfare maximizing equalization transfer}

We now turn to the problem of designing an equalization transfer program that maximizes social welfare, in a context where subnational autonomy is desirable but subject to self-interested (inefficient) decisions by local authorities. The design of the optimal level of equalization will need to satisfy the three conditions identified in the previous section. In this section we focus on the optimal amount of equalization transfers; the affordability of the transfer's system is analyzed in the next section.

The equalization transfer system is normally designed by an institutional body at a level higher than subnational governments, which is here assumed to be the central government. Formally, in order to arrive at the welfare maximizing transfer program we need to assume that the central government is benevolent. This assumption is made exclusively with the purpose of finding a sound policy design for the equalization transfer program; it is by no means to argue that the central government is in fact benevolent or that it may not be subject to similar incentives as subnational authorities.

\footnotetext{
${ }^{16}$ Emphasis in the original.
} 
In countries where subnational governments are responsible for providing local public goods and services, the central government usually determines common standards for subnational public expenditures and revenue effort, and delivers the amounts of transfers that allow all subnational governments to meet those standards. This strategy results in the system of equalization transfers, in which the ability to finance comparable or standard baskets of certain public goods and services is equalized across all governments of the same level.

The model developed in this section considers a central government and $J$ subnational jurisdictions of the same level. Each jurisdiction $j=1, \ldots, J$ is assumed to have one representative taxpayer. The central government applies a tax rate $t^{c}$ identically to all jurisdictions, and each subnational government retains autonomy to define its own tax rate $t^{j}$ inside its borders. ${ }^{17}$ For simplicity, we do not consider the potential mobility of the population or factors of production, nor any horizontal externality imposed by local tax and expenditure decisions. ${ }^{18}$

As pointed out above, in order to find the optimal level of equalization transfers the central government needs to satisfy the three conditions identified in the previous section. The ownrevenue condition deals with the more general problem of revenue assignments. Subnational governments must be given access to revenue sources from which they can effectively collect a significant amount of own revenue, as well as the discretional power to adjust the tax rates, if not the tax bases (Martinez-Vazquez, 2015; McLure, 2000).

\footnotetext{
${ }^{17}$ The local tax base $B^{j}$ may or may not be shared between the subnational and the central government. Either the subnational tax rate or the central tax rate could be set equal to zero to represent a tax instrument that has been assigned exclusively to the central or subnational government, respectively.

${ }^{18}$ Mobility may affect the optimal central government decisions through its effects on tax bases, but it is treated as an exogenous variable that does not alter the prevailing normative goals of welfare maximization and (partial or full) equalization. Horizontal fiscal externalities may also be relevant, but their effects on optimal revenue structure at the national and local levels are of a similar nature to those of vertical fiscal externalities considered in the next section.
} 
The incentive-compatibility condition suggests that the design of the equalization transfer system should help encourage responsive and efficient government behavior, while providing taxpayers with incentives to hold local authorities accountable. In order to encourage government responsiveness, we argue that equalization transfers should be determined under the normative assumption of full responsiveness, or $\rho=1$. This assumption implies that a jurisdiction cannot be compensated for the irresponsive behavior of its authorities. This means that the representative taxpayer in each jurisdiction bears the full cost of electing self-interested government authorities. ${ }^{19}$ If this were not the case, the rewards of lower responsiveness would lead to inefficient expenditure policies and to a soft budget constraint problem. ${ }^{20}$ By assuming $\rho=1$, therefore, we make sure that the equalization transfer system helps the accountability mechanisms to work locally. In order to encourage government efficiency, and as is common in both the theoretical and applied literatures, we define a standard level of tax effort. Standard tax effort is jointly defined by a standard tax rate $t^{S}$ and a standard administrative cost function $A^{S}$, both common to all jurisdictions. For the same $t^{s}$, administrative costs above the standard lead only to lower net revenue, not to more transfers. Similarly, when administrative costs are below the standard, net revenue may increase without affecting the amount of transfers to be received.

To address the expenditure autonomy condition we divide subnational public expenditures $G^{j}$ into two different categories. One consists of standard public expenditures per capita $G^{s}$, which are meant to be fully financed by a mix of equalization transfers $T^{j}$ and by own revenues collected

\footnotetext{
${ }^{19}$ Reduced responsiveness affects the actual tax rates and thus may impose tax externalities on other government units. We deal with vertical tax externalities in Section 4.

${ }^{20}$ The literature on the soft budget constraint focuses on the problems created by the use of transfers to assist governments under financial stress, which suggests that intergovernmental transfers can actually be influenced by the behavior of subnational governments (see Rodden, Eskeland and Litvack 2003). Accordingly, a number of empirical studies treat intergovernmental transfers as an endogenous variable (Knight 2002; Gordon 2004; Dahlberg et al 2008). In our discussion, we disregard this source of endogeneity and focus only on the normative aspects of subnational finances.
} 
under a standard level of tax effort. Standard public expenditures $G^{S}$ can be interpreted as the cost of providing a common (or perhaps a minimum) bundle of public goods and services to the representative taxpayer of each jurisdiction. The specific public goods and services included in the subnational standard are assumed exogenous, and may be considered as "necessary" for the representative taxpayers.

The other category consists of non-standard, autonomous, and discretional public expenditures $G^{d j}$. Under this category, we might include the same public goods and services considered in the standard package, but only to the extent that they deviate from that standard level of provision, or other public goods that the subnational government discretionally chooses to provide and that are not part of the national standard package. Positive amounts of discretional public expenditures should be financed entirely with own revenue collections. ${ }^{21}$ The distinction between standard and discretional expenditures is important to model central government intervention in a system where subnational governments are granted some degree of fiscal autonomy. In such a system subnational governments are allowed to offer different amounts and types of public goods and services, and the central government cannot, and should not, account for those differences when distributing equalization transfers.

Formally, with the objective of maximizing the sum of utilities of the representative taxpayers, the problem of designing the optimal equalization transfer system can be based on the following Lagrangian expression:

\footnotetext{
${ }^{21}$ Note that to the extent that subnational governments enjoy budget decision autonomy, in certain cases they could decide to provide "tax reductions" to the taxpayers, such that the discretional tax rate $t^{j}$ can possibly have negative values.
} 


$$
\begin{gathered}
\mathcal{L}^{s}=\sum_{j=1}^{J} u^{j}\left(X^{j}, G^{s}, G^{d j}, G^{c}\right)+\mu^{s j}\left\{-G^{s}+t^{s} B^{j}-A^{s}\left[t^{s} B^{j}\right]+T^{j}\right\} \\
+\mu^{c}\left\{-G^{c}-\sum_{j=1}^{J} T^{j}+t^{c} B-A^{c}\left[t^{c} B\right]\right\}(7)
\end{gathered}
$$

where $B=\sum_{j=1}^{J} B^{j}$, both $X^{j}$ and $B^{j}$ are functions of $t=t^{e}+t^{j}+t^{c}$, and $\mu^{s j}$ and $\mu^{c}$ are the Lagrange multipliers associated with the budget constraints of standard subnational expenditures and the central government. The first order condition for the optimal amount of equalization transfers $T^{j *}$ is given by

$$
T^{j}: \mu^{s j}-\mu^{c}=0, j=1, \ldots, J
$$

The optimal vector of intergovernmental transfers must make the marginal cost of standard own revenue collections in any jurisdiction $j$ equal to the marginal cost of own revenues at the central level. In other words, at the optimal solution, the marginal cost of financing standard public expenditures should be identical for all government units across the country. Using (8.a), the first order conditions for the optimal national standard of subnational public goods $G^{s *}$ and the optimal standard subnational tax rate $t^{S *}$ can be written as:

$$
\begin{gathered}
G^{s}: \frac{\sum_{j=1}^{J} u_{G^{s}}^{j}}{J}=\mu^{c}(8 . \mathrm{b}) \\
t^{s}: \frac{-\sum_{j=1}^{J} X_{t}^{j} u_{X^{j}}^{j}}{\sum_{j=1}^{J}\left(B^{j}+t^{s} B_{t}^{j}-A_{t^{s}}^{s}\right)+t^{c} B_{t}-A_{t^{s}}^{c}}=\mu^{c}(8 . \mathrm{c})
\end{gathered}
$$

where we have used $B_{t}^{j}=B_{t^{s}}^{j}$. Following Mayshar and Yitzhaki (1995), we can combine (8.b) and (8.c) to express the social marginal cost of funds of standard revenue collections, $S M C F^{s}$, as the product of an efficiency and an equity component. Equating the left hand sides of (8.b) and (8.c), dividing by the average marginal utility of income $\bar{u}_{X}=\sum_{j=1}^{J} u_{X^{j}}^{j} / J$, multiplying by $\sum_{j=1}^{J} X_{t}^{j} / \sum_{j=1}^{J} X_{t}^{j}$ and rearranging, we obtain 


$$
\frac{\sum_{j=1}^{J} u_{G^{s j}}^{j} / J}{\bar{u}_{X}}=\frac{-\sum_{j=1}^{J} X_{t}^{j}}{\sum_{j=1}^{J}\left(B^{j}+t^{s} B_{t}^{j}-A_{t^{s}}^{S}\right)+t^{c} B_{t}-A_{t^{s}}^{c}} \cdot \frac{-\sum_{j=1}^{J} X_{t}^{j} u_{X}^{j} / \bar{u}_{X}}{-\sum_{j=1}^{J} X_{t}^{j}}
$$

The first expression in the right hand side is the marginal efficiency cost of funds, $M E C F^{s}$, which increases with the negative externality of $t^{S}$ on central government revenue collections, $t^{c} B_{t}-$ $A_{t^{s}}^{c}$. The second expression is Feldstein's (1972) “distributional characteristic" of standard own revenue collections, $D C^{s}$. When either $X_{t}^{j}$ or $u_{X}^{j}$ are the same in all jurisdictions, then $D C^{s}=1$ and $t^{S}$ has no distributional effects. In contrast, if the tax rate has a smaller effect on consumption in jurisdictions with greater marginal utility of income (likely those that are poorer), then $D C^{s}<1$, which means that inequalities are reduced. This implies that the social costs of tax collections are partially offset by the social benefits of redistribution. We can conclude that the greater the redistributive effects of the equalization transfer system, the greater the standard tax rate $t^{S *}$ that should be required from subnational governments.

Moreover, if for a moment we make the unrealistic assumptions that subnational authorities are fully responsive welfare maximizers, that their expenditure decisions consider only standard (not discretional) public expenditures, and that they address the tax externalities they impose on the central government, then their problem can be represented by (7), and the first order conditions for the choice of the standard tax rate in each jurisdiction, $t^{s j}$, can be written as

$$
\mu^{s j}=u_{X}^{j} \frac{-X_{t}^{j}}{B^{j}+t^{s} B_{t}^{j}-A_{t^{s}}^{s}+t^{c} B_{t}^{j}-A_{t^{s}}^{c}}=u_{X}^{j} M C F^{s j}, j=1, \ldots, J
$$

Using the definition of $S M C F^{s}$ in (9) as well as the equalization condition in (8.a), it must be true that under the optimal solution

$$
\bar{u}_{X} S M C F^{s}=u_{X}^{j} M C F^{s j}, j=1, \ldots, J
$$

An analogous result in the related literature has shown that the distributionally-weighted MCFs are equalized across all government units (Dahlby 2009), and that the ratio of the MCFs of 
the two subnational governments is inversely related to the ratio of their distributional weights (Dahlby and Wilson 1994). ${ }^{22}$ Different from these results, however, condition (11) applies only to the provision of standard public expenditures, and it is explicitly based on several ideal assumptions that cannot realistically describe actual government behavior.

Still, condition (11) is useful because it provides a normative framework where we can define the basic constructs of the fiscal gap approach to designing equalization grants. In the remains of this section we introduce formal definitions of expenditure needs and fiscal capacity, and use them to characterize the fiscal gap as a sufficient approach to the optimal assignment of equalization transfers.

\subsection{Expenditure needs and fiscal capacity}

The concepts of fiscal capacity and expenditure needs are the two fundamental building blocks of most equalization transfer programs designed around the world. These programs are based on the fiscal gap formula, computed as the difference between estimate of expenditure needs and estimate of fiscal capacity.

What is the theoretical rationale for expenditure needs and fiscal capacity? To answer this question, we proceed to define the concepts of expenditure needs, fiscal capacity, and vertical and horizontal fiscal imbalances. We use Figure 2 to illustrate the definitions for these concepts for any given jurisdiction, so the symbol $j$ can be omitted to simplify notation. But first, some setting up. The horizontal axis represents only those goods and services subject to equalization. With no transfers, the equilibrium is $e^{1}$, on the intersection between the marginal benefit function and marginal cost function $M C F^{s^{\prime}}$, which is defined in accordance to (10). Using asterisks to represent

\footnotetext{
${ }^{22}$ In a utilitarian welfare function with representative taxpayers, different jurisdictions have the same social weight. In this context, the traditional concept of distributional weight, given by $\frac{\partial W}{\partial u^{j}} u_{X}^{j}$, is simplified to $u_{X}^{j}$.
} 
the optimal solution, the optimal amount of transfers $T^{*}$ shifts the function $M C F^{s \prime}$ to $M C F^{s \prime \prime}$, moving the equilibrium to $e^{*}$. As a result, the MCF decreases to $\mu^{S *} / u_{X}$ and the amount of standard public expenditures increases to $R^{S *}+T^{*}$.

Now, fiscal capacity or own revenue potential, $F C$, is defined as the amount of own revenues that a (fully responsive) subnational government would be able to collect at the optimal MCF under the optimal standard level of tax effort. Formally, the fiscal capacity of any jurisdiction is

$$
F C=R^{S *}
$$

This definition is largely compatible with the traditional measurement of fiscal capacity, according to which fiscal capacity corresponds to the ability to raise own revenues from the assigned tax bases given a standard level of tax effort. ${ }^{23}$ In practice, however, it is not clear how full responsiveness translates into budgetary decisions, and it is not possible to estimate fiscal capacity under the full responsiveness assumption. ${ }^{24}$ Because of this reason, applied economists rely on the more pragmatic assumption - implicit in fiscal capacity methodologies - of "average" tax effort and responsiveness.

Similarly, expenditure needs, $E N$, is defined as the optimal amount of standard public expenditures that the subnational government should provide at the optimal MCF. Formally, the expenditure needs of any jurisdiction are defined as:

$$
E N=R^{S *}+T^{*}
$$

\footnotetext{
${ }^{23}$ See, for example, Boex and Martinez-Vazquez (2007). This definition differs from the one provided in Dahlby (2009), in which the tax base is divided by its tax elasticity in order to account for the negative effect of the sensitivity of the tax base on fiscal capacity. We do not do that, however, because the sensitivity of the tax base is already accounted for by the slope of the MCF function.

${ }^{24}$ Methodologies to estimating fiscal capacity can be found, for instance, in U.S. Advisory Commission on Intergovernmental Relations (1986) and Boex and Martinez-Vazquez (2007).
} 
This definition is compatible with the traditional notion of expenditure needs, typically related to a "comparable" or "standard" package of goods and services, which is made affordable by the transfers received and the fiscal capacity of the jurisdiction. ${ }^{25}$

As indicated already above, the fiscal gap of any jurisdiction, denoted by $F G$, can be defined as

$$
F G=E N-F C
$$

A positive fiscal gap means that the amount of revenues raised under a given level of tax effort are not enough to cover the expenditure needs of the jurisdiction, and thus additional resources in the form of equalization transfers are required in order to provide a standard bundle of public goods and services. In contrast, a negative fiscal gap implies that the jurisdiction has a "surplus" and is able to provide more or better public services without any financial assistance.

\section{Figure 2}

Fiscal capacity, expenditures needs and optimal equalization transfers

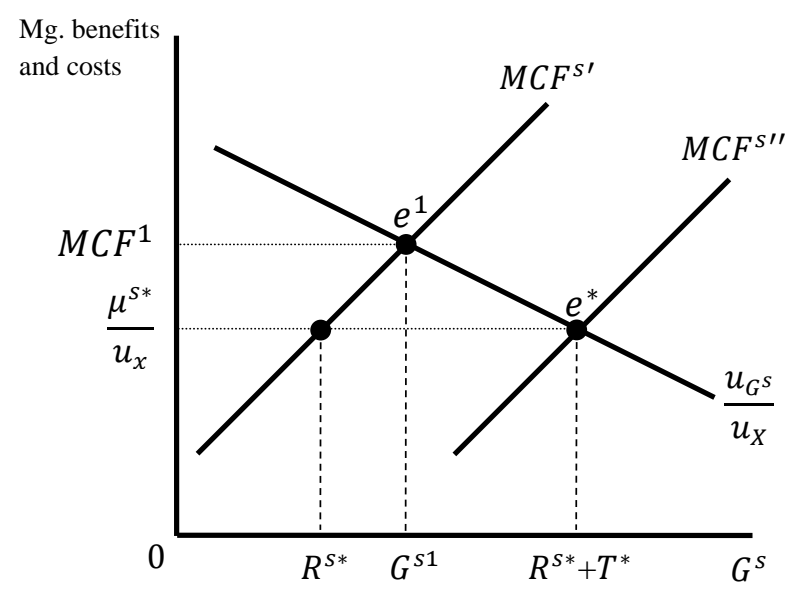

\footnotetext{
${ }^{25}$ A discussion about the concept, measurement methodologies, and use of expenditure needs estimates is provided, for example, by Boex and Martinez-Vazquez (2007).
} 


\subsection{Horizontal and vertical fiscal imbalances}

Given that expenditure needs and tax bases vary widely across jurisdictions, it is normal to observe significant differences in the value of fiscal gaps among governments of the same level. These differences are known as horizontal imbalances, and equalization transfers are typically aimed to eliminating, or at least reducing, these imbalances. In practice, countries make use of three possible equalization strategies. Some distribute equalization transfers in accordance to relative expenditure needs only; others attempt to equalize only the differences in fiscal capacity, and others consider both factors simultaneously and attempt to equalize fiscal gaps (Boex and Martinez-Vazquez, 2007; Dafflon, 2007). To the extent that one additional monetary unit of expenditure needs has exactly the same impact on the public budget as the reduction of one monetary unit of fiscal capacity, both factors are equally important and the equalization of fiscal gaps can be regarded as the best approach to equalization. Indeed, the optimal transfer vector under condition (11) can be seen as an equalization transfer program that equalizes fiscal gaps across all jurisdictions of the same level.

The differences observed in the design and depth of the expenditure and revenue decentralization assignments lead to different fiscal gaps across levels of government. These differences are usually referred to as vertical fiscal imbalances, and any transfer - including general tax sharing - from the government level with a negative fiscal gap (usually the central government) to the government level with positive fiscal gap (usually subnational governments) would help reduce the vertical imbalances. Given the standard public expenditures and tax effort, 
the size of the vertical imbalance VI between the central and subnational governments under the optimal solution described in $(11)$ is given by: ${ }^{26}$

$$
V I=\sum_{j=1}^{J} F G^{j} \cdot(15)
$$

Under the same assumptions, we can also define horizontal imbalances as the differences in fiscal gaps across governments of the same level. By using our definition of fiscal gap, therefore, we can clearly define the concepts of vertical and horizontal imbalances. ${ }^{27}$

If the subnational governments with negative fiscal gaps transfer all their surpluses to the subnational governments with positive fiscal gaps, the size of the vertical imbalance would be equal to the total amount of transfers required to fully close the horizontal imbalances only. ${ }^{28}$ More commonly, however, governments with negative fiscal gaps do not contribute to the equalization transfer fund and thus the amount of resources required to fully eliminate the horizontal imbalances is greater than the vertical imbalance. As a consequence, neither the horizontal nor the vertical fiscal imbalances will be closed optimally (Boadway and Tremblay, 2006).

There are a number of possible limitations to the ability of the system to close fiscal gaps. Besides the impossibility of collecting contributions from (richer) jurisdictions with negative fiscal gaps, countries use transfers to fulfill objectives different from equalization, like pro-poor programs or infrastructure investments. The resources used for these purposes will help to close the vertical imbalance, but not necessarily the horizontal imbalances. As the central government is

\footnotetext{
${ }^{26}$ There is no clear agreement in the literature about the right terminology to define these concepts. Boadway and Tremblay $(2006,2010)$, for example, use the term 'fiscal gap' to refer to what we call here vertical imbalance, and in turn they use the term 'fiscal imbalance' to refer to deviations from the optimal equilibrium.

${ }^{27}$ Bird and Tarasov (2004) argue that the two concepts cannot be cleanly separated, and for that purpose, they suggest considering the vertical imbalance closed at the point where the fiscal gap of the wealthiest jurisdiction is zero.

${ }^{28}$ Such an arrangement is known as the "fraternal" (or Robin Hood) approach to equalization, and it is relatively common among European countries.
} 
unable to reduce the marginal cost of funds nationwide to the optimal level, there will be a downward adjustment to the standard of expenditure needs that can be guaranteed by the system.

In general, note that in order to implement an equalization transfer program that reduces horizontal imbalances, it is not necessary to know the marginal cost of funds' functions faced by each subnational government. In practice, it is sufficient to define the national standards for the provision of public goods and services and the national standard of tax effort for the collections of revenues, and to disburse the equalization transfers in accordance with the estimated fiscal gaps. This is the point where the formal theory of revenue assignments meets the practice of equalization transfer implementation using a fiscal gap approach. Policy makers do not need to understand the theoretical underpinnings of the fiscal gap model; instead, they can rely on estimations of expenditure needs and fiscal capacity of the different subnational governments.

\section{Ensuring affordability and addressing vertical tax externalities}

The concepts of standard public expenditures and standard tax effort are relevant only for the purpose of computing the optimal equalization transfer vector, and do not guarantee in any way that the transfers arrived at are actually affordable within existing budgets. In this section we focus on the problem of ensuring affordability of the equalization transfer system. From the perspective of the central government, this problem is simultaneous, but different in nature, from the normative problem of what amount of equalization transfers subnational governments should receive. We assume that subnational governments know the amounts of equalization transfers that they will receive when choosing their optimal tax rates, and do not take into account the possible effects of their current fiscal decisions on future equalization transfers. These assumptions seem plausible if we consider that the fiscal gap formula uses expenditure needs instead of actual expenditures, and

fiscal capacity instead of actual revenues; and that in practice it is difficult for subnational 
governments to affect either component of the formula. ${ }^{29}$ The central government is assumed to take subnational responses into account when deciding about the tax rates that will ensure the affordability of the system.

Once optimal equalization transfers have been determined, each jurisdiction should enjoy some degree of freedom to select the amount of standard and discretional public goods and services that best fit local preferences (the expenditure autonomy condition). The greater the demand for public goods and services, the greater the need for tax revenue and thus the higher the optimal MCF in the jurisdiction. In this context, the actual level of tax effort should be expected to vary with the preferences and characteristics of each community, and there is nothing inherently wrong with choosing to exert lower or higher tax efforts than the average jurisdiction.

Subnational autonomy also implies that the amount of funds available to the central government, and thus the optimal choice of the central government tax rate $t^{c}$, is subject to the actual fiscal decisions of subnational authorities. In order to model the behavior of self-interested subnational authorities in the presence of standard and discretional public expenditures, we need to adjust the objective function used in Section 2. We use $R^{s}=t^{s} B(t)-A^{s}\left[t^{s} B(t)\right]$, define discretional own revenue $R^{d}=t B(t)-A\left[\left(t^{s}+t\right) B(t)\right]+A^{s}\left[t^{s} B(t)\right]$, and drop the superscript $j$ for clarity. In addition, considering that marginal political gains have been assumed to be equal to marginal net fiscal benefits, we abuse notation slightly and represent political support with the

\footnotetext{
${ }^{29}$ Still, the theoretical and applied literatures recognize that subnational government may consider in certain cases the effect of their fiscal decisions on equalization transfers. For instance, Smart (1998) explains that when transfers are based on the observed tax base, an increase in local taxes that erode the tax base $\left(B_{t}<0\right)$ would lead to a reduction of tax revenue collected under standard tax effort and so an increase of equalization transfers. One simple way to minimize the manipulation of standard tax revenue by subnational governments is to average the last 3 or 5 year estimates of fiscal capacity in order to delay the effect of fiscal decisions on transfers. If transfers are assigned in accordance to (14) and fiscal capacity is averaged over $n$ years, then a reduction of one dollar of fiscal capacity in the current period will lead to an increase of equalization transfers of only $1 / n$ dollar.
} 
utility function $u=u\left(X(t), G^{s}, G^{d}, G^{c}\right)$. The problem faced by the self-interested subnational authorities can be represented by the following Lagrangian expression:

$$
\begin{aligned}
\mathcal{L}^{j} & =u\left(X(t), G^{s}, G^{d}, G^{c}\right)+(1-\rho)\left(R^{s}+R^{d}+T^{*}\right) \\
& +\delta^{s}\left\{-G^{s}+\rho\left(R^{s}+T^{*}\right)\right\}+\delta^{d}\left\{-G^{d}+\rho R^{d}\right\}
\end{aligned}
$$

where $\delta^{s}$ and $\delta^{d}$ are the Lagrangian multipliers of standard and discretional subnational expenditures, respectively. The first order conditions for the optimal choices of the discretional tax rate $t$ and government responsiveness $\rho$ are

$$
\begin{gathered}
t: X_{t} u_{X}+(1-\rho)\left(R_{t}^{s}+R_{t}^{d}\right)+\rho\left(\delta^{s} R_{t}^{s}+\delta^{d} R_{t}^{d}\right)=0,(16 . \mathrm{a}) \\
\rho:-\left(R^{s}+R^{d}+T^{*}\right)+\delta^{s}\left(R^{s}+T^{*}\right)+\delta^{d} R^{d}=0,(16 . \mathrm{b})
\end{gathered}
$$

which are analogous to (3.a) and (3.b). ${ }^{30}$

Defining $R^{c}=t^{c} B(t)-A^{c}\left[t^{c} B(t)\right]$, the problem of the central government, which needs to ensure affordability of public expenditures nationally while allowing for subnational discretion is represented by the following Lagrangian expression:

$$
\begin{gathered}
\mathcal{L}^{c}=\sum_{j=1}^{J} u^{j}\left(X^{j}, G^{s}, G^{d j}, G^{c}\right) \\
+\sum_{j=1}^{J} \delta^{s j}\left\{-G^{s j}+\rho^{j}\left(R^{s j}+T^{j *}\right)\right\}+\delta^{d j}\left\{-G^{d j}+\rho^{j} R^{d j}\right\} \\
+\delta^{c}\left\{-G^{c}-\sum_{j=1}^{J} T^{j *}+R^{c}\right\} \cdot(17)
\end{gathered}
$$

Assuming for simplicity that the utility functions are separable in $G^{c}$, such that its value does not affect subnational decisions, the first order condition for its optimal choice is

$$
G^{c}: \quad \sum_{j=1}^{J} u_{G^{c}}^{j}=\mu^{c} .(18 . \mathrm{a})
$$

\footnotetext{
${ }^{30}$ When we make no distinction between standard and discretional expenditures we can define $\delta=\delta^{s}=\delta^{d}$, and from (16.b) we obtain $\delta=u_{G}=1$. Using this result, as well as $R_{t}=R_{t}^{S}+R_{t}^{d}$, condition (16.a) reduces to $X_{t} u_{X}+$ $R_{t}=0$. This last result can be rearranged to obtain the adjusted Samuelson condition in (5).
} 
Considering the effect of $t^{c}$ on the subnational decisions of $t^{j}$ and $\rho^{j}, j=1, \ldots, J$, which are represented by $t_{c}^{j *}$ and $\rho_{c}^{j *}$, and using (16.a) and (16.b), the first order condition for the optimal $t^{c}$ can be simplified to

$$
\begin{gathered}
t^{c}: \quad \sum_{j=1}^{J}\left\{X_{t}^{j} u_{X^{j}}^{j}+\rho^{j}\left(\delta^{s j} R_{t^{c}}^{s j}+\delta^{d j} R_{t^{c}}^{d j}\right)\right\} \\
+\delta^{c}\left(R_{t^{c}}^{c}+\sum_{j=1}^{J} t_{t^{c}}^{j *} R_{t^{j}}^{c}\right) \text { (18.b.ii) } \\
-\sum_{j=1}^{J} t_{t^{c}}^{j *}\left(1-\rho^{j}\right)\left(R_{t^{j}}^{s j}+R_{t^{j}}^{d j}\right) \text { (18.b.iii) } \\
+\sum_{j=1}^{J} \rho_{t^{c}}^{j *}\left(R^{s j}+R^{d j}+T^{j *}\right)=0 . \text { (18.b.iv) }
\end{gathered}
$$

The central government must increase $t^{c}$ up to the point where the marginal costs and marginal benefits cancel each other. Among the costs, (18.b.i) represents the reduction in private consumption and the provision of subnational public goods and services. Among the benefits, (18.b.ii) represents tax collections after accounting for subnational tax responses. Whether (18.b.iii) and (18.b.iv) correspond to costs or benefits of the central government tax policy will depend on the sign of $t_{t^{c}}^{j *}$ and $\rho_{t^{c}}^{j *}$. They would correspond to additional costs if $t^{c}$ has a positive effect on $t^{j *}$ and a negative effect on $\rho^{j *}$.

By endogenizing the response of subnational tax policy and responsiveness in its optimal tax decision, the central government can partially correct for inefficient subnational tax decisions. These inefficiencies arise because subnational governments typically ignore the negative externalities their decisions impose outside their jurisdictions. In particular, higher subnational tax rates can erode the tax bases within the jurisdiction and thus impose a negative vertical externality on the central government by reducing its tax revenues (Boadway and Keen 1996; Dahlby 1996; 
Boadway, Marchand and Vigneault 1998; Keen 1998; Dahlby and Wilson 2003). ${ }^{31}$ In order to identify these externalities in our model, we note that if the choice of the subnational tax rate $t^{j}$ were to account for all the social benefits and costs described in (17), its first order condition would be

$$
t^{j}: X_{t}^{j} u_{X^{j}}^{j}+\rho^{j}\left(\delta^{s j} R_{t^{j}}^{s j}+\delta^{d j} R_{t^{j}}^{d j}\right)+\delta^{c} R_{t^{j}}^{c}=0, j=1, \ldots, J
$$

The term $\delta^{c} R_{t^{j}}^{c}$ corresponds to the value of revenue lost by the central government due to a marginal increase of the subnational tax rate. A subnational government guided by the adjusted Samuelson condition in (5) ignores this cost, but the presence of this term in (18.b.ii) suggests that the central government can partially correct for it when deciding about the optimal amount of tax collections. This finding contrasts with the idea that the negative tax externalities associated with decentralized tax revenues should be fully corrected by the equalization transfer program in order to avoid inefficiencies and welfare losses. ${ }^{32}$ This correction might be justified. However, it should be so only on a differential basis because the externalities imposed by discretional tax decisions would likely differ across jurisdictions. This differential correction can be understood as an adjustment to the marginal cost of funds faced by each jurisdiction, and it would lead to an adjustment to the optimal equalization vector implicitly described by (11).

\footnotetext{
${ }^{31}$ Revenue externalities (positive or negative) can also be imposed on governments of the same level, but we have ruled out this possibility for simplifying purposes. In any case, the effects and implications of horizontal externalities are similar to those of vertical externalities. See, for instance, Gordon (1983) and Bucovetsky and Smart (2006).

${ }^{32}$ Bucovetsky and Smart (2006) and Kotsogiannis (2010) describe the modifications required by a standard equalization transfer formula in order to achieve efficient subnational taxation in the presence of horizontal and vertical tax externalities, respectively.
} 


\section{Conclusions}

In this paper, we have shown that the fiscal gap model used by applied economists around the world in the design of equalization grants is compatible with a 'holistic' approach that integrates practical as well as normative considerations. The fiscal gap model is largely compatible with some of the findings of the (less holistic) previous theoretical literature on the design of equalization transfers based on optimal tax theory, but the latter is shown to disregard some key issues that are relevant for the implementation of an optimal equalization transfer program. These issues include the need to account for discretional subnational decisions, the negative effects of transfers on responsiveness, and the consequent need to introduce accountability mechanisms.

The framework presented in this paper is divided in three stages. The first stage deals with the problem of limited government responsiveness and the need for accountability mechanisms. In this regard we examine two questions: Is the devolution of sufficient own revenue sources a precondition for a well-functioning equalization transfer program, and must the equalization transfer program must be incentive-compatible by rewarding efficiency and government responsiveness? The second stage focuses on the design of an optimal equalization transfer program. In line with commonly accepted international practices, we assume that the goal of the equalization transfer program is to ensure that all subnational governments are able to provide a standard level of public goods and services at a standard level of tax effort, while promoting efficient fiscal decisions. In order to obtain the optimal amount of equalization transfers that fulfill this goal, we distinguish standard subnational expenditures subject to equalization from discretional subnational expenditures that should be financed solely with own revenue sources. Under this framework we provide formal, yet simple, definitions for expenditure needs, fiscal 
capacity, fiscal gap and fiscal imbalances. The third stage focuses on the central government decision about the level of its tax rate, which ensures the affordability of the system.

The most important contribution in this paper is to show that the fiscal gap model is sufficient to implement an optimal equalization transfer program and that the implementation of this type of program requires only the estimation of expenditure needs and fiscal capacity. Therefore, central government authorities and politicians do not need to try to find out what is the marginal cost of public funds across jurisdictions.

For future research, there are several aspects of the framework introduced here that could be extended, including the use of single representative-taxpayer jurisdictions, the absence of mobility and other horizontal externalities, or the ability to take into account positive fiscal externalities from expenditure policies. 


\section{References}

Auerbach, Alan and James Hines. 2002. "Taxation and Economic Efficiency," In A. Auerbach and M. Feldstein, Handbook of Public Economics. Elsevier, 1347-421.

Bahl, Roy and Jorge Martinez-Vazquez. 2006. "Sequencing Fiscal Decentralization," Policy Research Working Paper 3914. Washington, D.C.: The World Bank,

Ballard, Charles L. and Don Fullerton. 1992. "Distortionary Taxes and the Provision of Public Goods." The Journal of Economic Perspectives, 6(3), 117-31.

Bandiera, Oriana, Andrea Prat and Tommaso Valletti. 2009. "Active and passive waste in government spending: evidence from a policy experiment." American Economic Review, 99(4), 1278-1308.

Bardhan, Pranab. 2002. "Decentralization of Governance and Development." The Journal of Economic Perspectives, 16(4), 185-205.

Besley, Timothy and Stephen Coate. 2003. "Centralized Versus Decentralized Provision of Local Public Goods: A Political Economy Analysis." Journal of Public Economics, 87(12), 261137.

Bird, Richard M. and Michael Smart. 2002. "Intergovernmental Fiscal Transfers:

International Lessons for Developing Countries." World Development, 30(6), 899-912.

Bird, Richard M. and Andrey V. Tarasov. 2004. "Closing the Gap: Fiscal Imbalances and Intergovernmental Transfers in Developed Federations." Environment and Planning C: Government and Policy, 22(1), 77-102.

Blöchliger, Hansjörg and Claire Charbit. 2008. Fiscal Equalisation by OECD Economic Studies No. 44, 2008/1. OECD.

Boadway, Robin; Katherine Cuff and Maurice Marchand. 2003. "Equalization and the Decentralization of Revenue-Raising in a Federation." Journal of Public Economic Theory, 5(2), 201-28.

Boadway, Robin and Michael J. Keen. 1996. "Efficiency and the Optimal Direction of Federal-State Transfers." International Tax and Public Finance, 3(2), 137-55.

Boadway, Robin; Maurice Marchand and Marianne Vigneault. 1998. "The Consequences of Overlapping Tax Bases for Redistribution and Public Spending in a Federation." Journal of Public Economics, 68(3), 453-78.

Boadway, Robin W. and Frank R. Flatters. 1982. "Efficiency and Equalization Payments in a Federal System of Government: A Synthesis and Extension of Recent Results." Canadian Journal of Economics, 15(4), 613-33.

Boadway, Robin and Anwar Shah (Eds.) 2007. Intergovernmental Fiscal Transfers: Principles and Practice. Washington D.C.: The World Bank.

Boadway, Robin and Jean-Francois Tremblay. 2006. "A Theory of Fiscal Imbalance." FinanzArchiv, 62(1), 1-27. . 2010. "Mobility and Fiscal Imbalance." National Tax Journal, 63(4, part 2), 1023-54. 
Boex, Jameson and Jorge Martinez-Vazquez. 2007. "Designing Intergovernmental Equalization Transfers with Imperfect Data: Concepts, Practices and Lessons," J. Martinez-Vazquez and B. Searle, Fiscal Equalization: Challenges in the Design of Intergovernmental Transfers. New York, NY: Springer.

Brollo, Fernanda; Tommaso Nannicini, Roberto Perotti, and Guido Tabellini. 2013. "The Political Resource Curse." American Economic Review, 103(5), 1759-96.

Buchanan, James M. and Charles J. Goetz. 1972. "Efficiency Limits of Fiscal Mobility: An Assessment of the Tiebout Model." Journal of Public Economics, 1(1), 25-43.

Buchanan, James M. and Richard E. Wagner. 1970. "An Efficiency Basis for Federal Fiscal Equalization," The Analysis of Public Output. National Bureau of Economic Research, Inc., 139-62.

Bucovetsky, Sam and Michael Smart. 2006. "The Efficiency Consequences of Local Revenue Equalization: Tax Competition and Tax Distortions." Journal of Public Economic Theory, 8(1), 119-44.

Dafflon, Bernard. 2007. "Fiscal Capacity Equalization in Horizontal Fiscal Equalization Programs," R. Boadway and A. Shah, Intergovernmental Fiscal Transfers; Principles and Practice. Washington, D.C.: The World Bank.

Dahlberg, Matz; Eva Mörk; Jørn Rattsø and Hanna Ågren. 2008. "Using a Discontinuous Grant Rule to Identify the Effect of Grants on Local Taxes and Spending." Journal of Public Economics, 92(12), 2320-35.

Dahlby, Bev. 1996. "Fiscal Externalities and the Design of Intergovernmental Grants." International Tax and Public Finance, 3(3), 397-412.

. 2008. The Marginal Cost of Public Funds: Theory and Applications. Cambridge, Mass.: MIT Press.

. 2009. "The Optimal Taxation Approach to Intergovernmental Grants," Working Papers 200916. Edmonton, Alberta: Department of Economics, University of Alberta,

Dahlby, Bev and Leonard S. Wilson. 1994. "Fiscal Capacity, Tax Effort, and Optimal Equalization Grants." The Canadian Journal of Economics, 27(3), 657-72.

2003. "Vertical Fiscal Externalities in a Federation." Journal of Public Economics, 87(5-6), 917-30.

Faguet, Jean-Paul. 2004. "Does decentralization increase government responsiveness to local needs? Evidence from Bolivia.” Journal of Public Economics, 88(3-4), 867-93.

Feldstein, Martin S. 1972. "Distributional Equity and the Optimal Structure of Public Prices." The American Economic Review, 62(1), 32-36.

Flatters, Frank R.; Vernon Henderson and Peter M. Mieszkowski. 1974. "Public Goods, Efficiency, and Regional Fiscal Equalization." Journal of Public Economics, 3(2), 99-112.

Gadenne, Lucie. 2017. "Tax Me, But Spend Wisely? Sources of Public Finance and Government Accountability.” American Economic Journal: Applied Economics, 9(1), 274-314. 
Gordon, Nora. 2004. "Do Federal Grants Boost School Spending? Evidence from Title I." Journal of Public Economics, 88(9-10), 1771-92.

Gordon, Roger H. 1983. "An Optimal Taxation Approach to Fiscal Federalism." The Quarterly Journal of Economics, 98(4), 567-86.

Håkonsen, Lars. 1998. "An Investigation into Alternative Representations of the Marginal Cost of Public Funds." International Tax and Public Finance, 5(3), 329-43.

Hettich, Walter and Stanley Winer. 1984. "A Positive Model of Tax Structure." Journal of Public Economics, 24(1), 67-87.

Keen, Michael J. 1998. "Vertical Tax Externalities in the Theory of Fiscal Federalism." IMF Staff Papers, 45(3), 454-85.

Knight, Brian G. 2002. "Endogenous Federal Grants and Crowd-out of State Government Spending: Theory and Evidence from the Federal Highway Aid Program." American Economic Review, 92(1), 71-92.

Kotsogiannis, Christos. 2010. "Federal Tax Competition and the Efficiency Consequences for Local Taxation of Revenue Equalization." International Tax and Public Finance, 17(1), 1-14.

Liu, Yongzheng and Jianmei Zhao. 2011. "Intergovernmental fiscal transfers and local tax efforts: evidence from provinces in China." Journal of Economic Policy Reform, 14(4), 295-300.

Lockwood, Ben. 2002. "Distributive Politics and the Benefits of Decentralization." Review of Economic Studies, 69(2), 313- 38.

Lockwood, Ben. 2005. "Fiscal Decentralization: A Political Economy Perspective." The Warwick Economics Research Paper Series (TWERPS), University of Warwick, Department of Economics.

Martinez-Vazquez, Jorge. 2015. "Tax Assignments at the Regional and Local Levels," in E. Ahmad and G. Brosio (eds.) Handbook of Fiscal Federalism and Multilevel Finance. Cheltenham, UK: Edward Elgar.

Martinez-Vazquez, Jorge and Robert Searle, (Eds.) 2007. Fiscal Equalization: Challenges in the Design of Intergovernmental Transfers. New York, NY: Springer.

Mayshar, Joram and Shlomo Yitzhaki. 1995. "Dalton-Improving Indirect Tax Reform." The American Economic Review, 85(4), 793-807.

McLure, Charles E., Jr. 2000. "Tax Assignment and Subnational Fiscal Autonomy." Bulletin for International Fiscal Documentation, 54(12), 626-35.

Mieszkowski, Peter M. and Richard A. Musgrave. 1999. "Federalism, Grants and Fiscal Equalization." National Tax Journal, 52(2), 239-60.

Oates, Wallace E. 1972. Fiscal Federalism. New York: Harcourt Brace Jovanovich.

Paler, Laura (2013). "Keeping the Public Purse: An Experiment in Windfalls, Taxes, and the Incentives to Restrain Government." American Political Science Review, 104(7), 706-25.

Prud'homme, Rémy. 1995. "The Dangers of Decentralization." The World Bank Research Observer, 10(2), 201-220. 
Rodden, Jonathan A.; Gunnar S. Eskeland and Jennie Litvack eds. 2003. Fiscal Decentralization and the Challenge of Hard Budget Constraints. Cambridge, Massachusetts: The MIT Press.

Sato, Motohiro. 2000. "Fiscal Externalities and Efficient Transfers in a Federation." International Tax and Public Finance, 7(2), 119-39.

Scott, Anthony D. 1964. "The Economic Goals of Federal Finance." Public Finance, 19, 241-88.

Seabright, Paul. 1996. "Accountability and Decentralization: An Incomplete Contracts Model." European Economic Review, 40(1), 61- 90.

Slemrod, Joel and Shlomo Yitzhaki. 2002. "Tax Avoidance, Evasion, and Administration," A. Auerbach and M. Feldstein, Handbook of Public Economics. Elsevier, 1423-70.

Smart, Michael. 1998. "Taxation and Deadweight Loss in a System of Intergovernmental Transfers." The Canadian Journal of Economics, 31(1), 189-206.

Tanzi, Vito. 2000. "On Fiscal Federalism: Issues to Worry About," IMF Conference on Fiscal Decentralization. Washington, D.C.

U.S. Advisory Commission on Intergovernmental Relations. 1986. "Measuring State Fiscal Capacity: Alternative Methods and Their Uses," Information Report M-150. Washington, D.C.: U.S. Advisory Commission on Intergovernmental Relations. 


\section{Appendix I.}

The linearization of the system of first order conditions (2.a) and (2.b) can be written, in matrix form, as

$$
\left[\begin{array}{cc}
u_{t t}+(1-\rho) R_{t t} & u_{\rho t}-R_{t} \\
u_{\rho t}-R_{t} & u_{\rho \rho}
\end{array}\right] *\left[\begin{array}{l}
d t^{*} \\
d \rho^{*}
\end{array}\right]=-\left[\begin{array}{c}
u_{t T} \\
\rho u_{\rho \rho}-1
\end{array}\right] *[d T] \text { (A.I.1) }
$$

where the first matrix is the Hessian $H$. Using Cramer's rule, the effect of transfers $T$ on optimal government responsiveness $\rho^{*}$ is given by

$$
\frac{d \rho^{*}}{d T}=\frac{\left|\begin{array}{cc}
u_{t t}+(1-\rho) R_{t t} & -u_{t T} \\
u_{\rho t}-R_{t} & 1-\rho u_{\rho \rho}
\end{array}\right|}{\left|\begin{array}{cc}
u_{t t}+(1-\rho) R_{t t} & u_{\rho t}-R_{t} \\
u_{\rho t}-R_{t} & u_{\rho \rho}
\end{array}\right|}=\frac{\left(u_{t t}+(1-\rho) R_{t t}\right)\left(1-\rho u_{\rho \rho}\right)+\left(u_{\rho t}-R_{t}\right) u_{t T}}{\left(u_{t t}+(1-\rho) R_{t t}\right) u_{\rho \rho}-\left(u_{\rho t}-R_{t}\right)^{2}}
$$

which is equal to the result in the text.

\section{Appendix II. Derivation of (4)}

Since $T$ does not directly affect taxpayer's political support $\pi(t, \rho)$, the system in (A.I.1) becomes

$$
\left[\begin{array}{cc}
\pi_{t t}+(1-\rho) R_{t t} & \pi_{\rho t}-R_{t} \\
\pi_{\rho t}-R_{t} & \pi_{\rho \rho}
\end{array}\right] *\left[\begin{array}{l}
d t^{*} \\
d \rho^{*}
\end{array}\right]=\left[\begin{array}{l}
0 \\
1
\end{array}\right] *[d T] \text { (A.II.1) }
$$

Using Cramer's rule, the effect of $T$ on $\rho^{*}$ is given by

$$
\frac{d \rho^{*}}{d T}=\frac{\left|\begin{array}{cc}
\pi_{t t}+(1-\rho) R_{t t} & 0 \\
\pi_{\rho t}-R_{t} & 1
\end{array}\right|}{\left|\begin{array}{cc}
\pi_{t t}+(1-\rho) R_{t t} & \pi_{\rho t}-R_{t} \\
\pi_{\rho t}-R_{t} & \pi_{\rho \rho}
\end{array}\right|}=\frac{\pi_{t t}+(1-\rho) R_{t t}}{\left(\pi_{t t}+(1-\rho) R_{t t}\right) \pi_{\rho \rho}-\left(\pi_{\rho t}-R_{t}\right)^{2}}, \text { (A.II.2) }
$$

which is equal to (4). 